\title{
Identifikasi Nilai dan Kelas Tanah untuk Updating Nilai Jual Objek Pajak Bumi dan Bangunan di Kota Palopo
}

\author{
M. Zainal S ${ }^{*}$, Syafruddin ${ }^{1}$, M. Risal ${ }^{1}$, Muhammad Aqsa $^{1}$, Sapar $^{1}$
}

${ }^{1}$ Universitas Muhammadiyah Palopo, Indonesia

\author{
A R T I C L E I N F O \\ Article history: \\ Received 09 April 2021 \\ Accepted 12 Juni 2021 \\ Available online 30 Juni \\ 2021 \\ Kata Kunci: \\ Kelas Tanah; Nilai Tanah; \\ Harga Pasar; Palopo \\ Keywords: \\ Land Class; Land Value; \\ Market Price; Palopo
}

\begin{abstract}
A B S T R A K
Updating data objek dan subjek pajak bumi dan bangunan di Kota Palopo penting untuk dilakukan karena Nilai Jual Objek Pajak (NJOP) per-meter jauh lebih rendah dari nilai jual (pasar) saat ini. Pen elitian ini bertujuan mengidentifikasi nilai tanah dan kelas tanah untuk updating NJOP Bumi dan Bangunan di Kota Palopo. Menggunakan pendekatan kuantitatif dengan moteode survei. Teknik pengumpulan data melalui kuesioner, pengamatan langsung di lapangan dan wawancara mendalam dengan informan kunci baik dari perwakilan pemilik tanah maupun pegawai kelurahan. Analisis data menggunakan teknik kuantitatif deskriptif melalui pengecekan dan sinkronisasi data primer dengan data sekunder khususnya data Nilai Jual Objek Pajak (NJOP) tahun terakhir responden dan peraturan pemerintah (Keputusan Menteri Keuangan No
\end{abstract} 523/KMK.04/1998 tentang Klasifikasi Penggolongan dan Ketentuan Nilai Jual Tanah) untuk mengetahui gambaran kondisi tanah dan kelas tanah setiap responden yang tersaji pada Tabel 1-4. Hasil penelitian menunjukkan bahwa secara umum terdapat selisih kelas tanah setiap kecamatan di lokasi penelitian sehingga pemutakhiran kenaikan kelas tanah yang dilakukan Bapenda layak untuk dilaksanakan. Terdapat perbedaan antara nilai tanah berdasarkan NJOP dengan nilai tanah berdasarkan harga pasar di setiap kecamatan yang berbasis di kelurahan. Nilai tanah berdasarkan harga pasar di semua kelurahan setiap kecamatan tergolong tinggi. Nilai tanah tertinggi sebagian besar berada kecamatan Wara sebagai pusat ibu kota Palopo dengan penggunaan lahan sebagai pusat perdagangan dan jasa.

\begin{abstract}
A B S T R A C T
Updating data on objects and subjects of land and building taxes in Palopo City is essential because the Sales Value of Tax Objects (NJOP) per meter is much lower than the current selling value (market). This study aims to identify land values and land classes in updating the sale value of land and building tax objects and using a quantitative approach with a survey method, using cluster sampling technique by taking the sub-district representing the four districts. Each selected sub-district was drawn randomly, representing 33 respondents from each sub-district. Data collection techniques were through questionnaires, direct field observations, and in-depth interviews with key informants, both representatives of landowners and village officials. Data analysis uses descriptive quantitative methods through checking and synchronizing primary data with secondary data, especially data on the Sales Value of Tax Objects (NJOP) in the last year of respondents and government regulations (Decree of the Minister of Finance No. 523/KMK.04/1998 on Classification and Provisions for Land Sales Value) to find out the description of the soil condition and soil class of each respondent which is presented in Table 1-4. The results showed that, in general, there was a difference in soil class for each sub-district in the research location so that the updating of soil grade promotion by Bapenda was feasible to be implemented. There is a difference between the land value based on the tax object's selling value and the land value based on the market price in each district. The land value based on market prices in all sub-district in each section is high. The highest land values are primarily located in the Wara sub-district, the center of the capital city of Palopo, with land use as a center for trade and services.
\end{abstract}





\section{Pendahuluan}

Pemutakhiran data objek dan subjek pajak bumi dan bangunan dalam rangka pemeliharaan basis data objek dan subjek Pajak Bumi dan Bangunan Sektor Pedesaan dan Perkotaan (PBB-P2) Kota Palopo Tahun 2020 penting dilakukan. Beberapa alasan penting yang melatarbelakangi pelakasanaan kegiatan tersebut meliputi: sebagai tindak lanjut pelaksanaan Undang-Undang Nomor: 28 Tahun 2009 tentang Pajak Daerah dan Retribusi Daerah yang memberikan kewenangan kepada Kepala daerah untuk mengelola PBB-P2, banyaknya jumlah objek pajak di wilayah Kota Palopo dan beragamnya tingkat pendidikan dan pengetahuan wajib pajak namun belum seluruhnya wajib pajak dapat melaksanakan kewajibannya untuk mendaftarkan obyek pajak yang dikuasai/dimilikinya, pembiayaan pembangunan dan tuntutan kemandirian daerah mengharuskan untuk peningkatan potensi penerimaan pajak bumi dan bangunan, Nilai Jual Objek Pajak (NJOP) per-meter jauh lebih rendah dari nilai jual (pasar) dan Kenaikan NJOP sejalan dengan Kenaikan Penerimaan Pendapatan Asli Daerah (PAD) di Sektor Bea Perolehan Hak atas Tanah dan/atau Bangunan (BPHTB).

Nilai Jual Objek Pajak (NJOP) adalah harga rata-rata yang diperoleh dari transaksi jual beli yang terjadi secara wajar, dan bilamana tidak terdapat transaksi jual beli, NJOP ditentukan melalui perbandingan harga dengan objek lain yang sejenis, atau nilai perolehan baru, atau NJOP pengganti. Proses penentuan NJOP haruslah sesuai dengan ketentuan Nilai Pasar Wajar (NPW), jadi pemerintah tidak salah jika berharap NJOP adalah sama dengan nilai pasar. Jika NJOP berhasil disamakan dengan nilai pasar, diharapkan juga bahwa NJOP akan menjadi Single Value for Multi Purpose (SVMP) yang artinya NJOP tidak semata-mata digunakan untuk tujuan perpajakan, tetapi dapat juga digunakan untuk tujuan lain misalnya: pembebasan tanah, asuransi, penggabungan usaha, peleburan usaha dan pemekaran usaha (Aprianti B dan Waljiyanto, 2013)

Penilaian tanah merupakan proses untuk memberikan estimasi dan pendapat atas suatu properti (bumi dan bangunan), berdasarkan fakta-fakta yang dapat diterima, yang diperol eh dari penelitian di lapangan dan melakukan penyelidikan serta pemeriksaan (Harjanto \& Hidayati, 2016). Menurut Ernawati dalam (Ratna Kusumawardhani, Udiana Wahyu D, 2016) bahwa peningkatan harga tanah di suatu daerah akan berbeda dengan daerah lainnya dikarenakan adanya beberapa faktor yang dapat menjadi pemicu antara lain faktor ekonomi, faktor sosial, faktor politik dan kebijakan pemerintah, faktor fisik dan lingkungan. Nilai tanah adalah ukuran kemampuan tanah untuk menghasilkan atau memproduksi sesuatu secara langsung memberikan keuntungan ekonomis. Dalam konteks pasar properti nilai tanah sama dengan harga pasar tanah tersebut misalnya harga pasar tanah tinggi maka nilai tanahnya juga tinggi demikian pula sebaliknya (Sutawijaya, 2004).

Ketentuan Harga Zona Nilai Tanah pada kantor Pertanahan kota Palembang memberikan dampak positif bagi masyarakat karena harga yang ditetapkan jauh diatas standar harga permeter pada masyarakat. Namun masyarakat belum menyadari dan menjadikan Harga Zona Nilai Tanah sebagai referensi dalam melakukan transaksi jual beli dan juga sebagai pencegahan dan pengurangan sengketa, perkara dan konflik pertanahan (Heriyanto, Rifai Azmulian, 2016). Sedangkan pertimbangan pemerintah dalam menetapkan Zona Nilai Tanah (ZNT) sebagai dasar pemungutan penentuan Penerimaan Negara Bukan Pajak (PNBP) adalah sebagai jaminan 
kepastian hukum serta untuk meningkatkan Pendapatan Asli Daerah (PAD) guna sebagai pembangunan daerah (Maimanah et al., 2019). Berangkat dari permasalahan utama sebagaimana diuraikan khususnya terkait Nilai Jual Objek Pajak (NJOP) yang jauh lebih rendah dari nilai jual (pasar) tanah di Kota Palopo, maka penelitian ini bertujuan mengidentifikasi nilai tanah dan kelas tanah untuk updating Nilai Jual Objek Pajak Bumi dan Bangunan di Kota Palopo.

\section{Metode}

Penelitian ini menggunakan pendekatan kuantitatif dengan moteode survei yang dilaksanakan di Kota Palopo pada bulan April sampai Juni 2020. Penentuan sampel menggunakan teknik cluster sampling dengan mengambil beberapa Kelurahan yang mewakili Empat Kecamatan yaitu Kecamatan Wara, Wara Timur, Wara Utara, dan Wara Selatan. Setiap kelurahan yang terpilih dilakukan penarikan responden secara acak yang mewakili setiap kelurahan yang berjumlah 33. Pengumpulan data melalui kuesioner, pengamatan langsung di lapangan dan wawancara mendalam dengan informan kunci baik dari perwakilan pemilik tanah maupun pegawai kelurahan.

Jenis data yang dikumpulkan berupa data primer dan data sekunder. Data primer meliputi data jenis penggunaan tanah, kondisi topografi atau posisi tanah, dan data harga jual tanah terbaru. Data sekunder diperoleh dari instant terkait berupa: data Nilai Jual Objek Pajak (NJOP) tahun terakhir, Peraturan Daerah (Perda) tentang penggolongan NJOP dan Keputusan Menteri Keuangan No 523/KMK.04/1998 tentang Klasifikasi Penggolongan dan Ketentuan Nilai Jual Tanah. Data primer dan data sekunder yang telah dikumpulkan selanjutnya dilakukan analisis kuantitatif deskriptif. Data primer yang telah dikumpulkan kemudian dilakukan pengecekan dan sinkronisasi dengan data sekunder khususnya data terkait dengan Nilai Jual Objek Pajak (NJOP) tahun terakhir responden dan regulasi tentang Keputusan Menteri Keuangan No 523/KMK.04/1998 tentang Klasifikasi Penggolongan dan Ketentuan Nilai Jual Tanah yang bertujuan untuk mengetahui gambaran kondisi tanah dan kelas tanah setiap responden penelitian (tersaji pada Tabel 1 sampai 4).

\section{Hasil dan pembahasan}

Secara umum ajuan kenaikan NJOP dan kelas tanah yang dibuat oleh Bapenda Kota Palopo sebagai salah satu syarat penyesuaian Zona Nilai Tanah (ZNT) di Kecamatan Wara Timur berdasarkan temuan di lokasi penelitian sangat layak untuk diimplementasikan. Fakta di lokasi penelitian khususnya di Kecamatan Wara Timur ditemukan secara keseluruhan terdapat selisih kelas tanah responden (Tabel 1). Di kecamatan Wara Timur nilai tanah tertinggi berdasarkan harga pasar berada di kelurahan Ponjalae sebesar Rp. 650.000.00 dengan kelas tanah saat ini 19. Kondisi topografi kelurahan di kecamatan Wara Timur semuanya berada pada pesisir (BPS, 2019c). Penelitian (Bayhaki, Sunaryo, Kurnia, Dedy Yulianandha, 2019) terkait NJOP menemukan bahwa NJOP di Kecamatan Malak Tengah Kabupaten Malaka terbagi kedalam 8 kelas, dengan kelas tertinggi adalah kelas 76 dengan nilai Rp. 200.000 sedangkan kelas terendah adalah kelas 84 dengan nilai Rp. 27.000. 
Penelitian (Karakayaci, 2018) menganalisis faktor-faktor yang mempengaruhi nilai tanah di sub-distrik (Selcuklu, Meram, Karatay) di provinsi Konya Turkey menemukan bahwa perubahan lahan pertanian menjadi lahan perkotaan pada dasarnya mengarah pada peningkatan nilai lahan di dalam wilayah urban/kota. (Yang et al., 2020) bertujuan menganalisis faktor-faktor yang mempengaruhi distribusi harga lahan industri di Kota Dingzhou dan percontohan reformasi sistem pertanahan pedesaan di Cina menggunakan model geographically weighted regression (GWR) menunjukkan bahwa, faktor-faktor yang berkorelasi negatif dengan harga pengalihan lahan industri antara lain proporsi luas lahan garapan dan jarak ke kota. Sedangkan faktor-faktor yang berkorelasi positif dengan harga transfer lahan industri antara lain adalah laju pertumbuhan penduduk, laju pertumbuhan ekonomi, kepadatan penduduk, dan jumlah rumah sakit persatuan luas.

Tabel 1 Kondisi tanah dan kelas tanah di Kecamatan Wara Timur

\begin{tabular}{lllllllll}
\hline $\begin{array}{l}\text { Res } \\
\text { pon } \\
\text { den }\end{array}$ & Kelurahan & $\begin{array}{c}\text { Nilai } \\
\text { Tanah } \\
\text { yang Lalu }\end{array}$ & $\begin{array}{c}\text { Nilai Jual } \\
\text { Tanah Saat } \\
\text { Ini (/M) }\end{array}$ & $\begin{array}{c}\text { Kelas } \\
\text { Berdasark } \\
\text { an NJOP }\end{array}$ & $\begin{array}{c}\text { Kelas } \\
\text { Saat Ini }\end{array}$ & $\begin{array}{c}\text { Jumlah } \\
\text { Kenaikan } \\
\text { Kelas }\end{array}$ & $\begin{array}{c}\text { Selisih } \\
\text { Kelas }\end{array}$ & $\begin{array}{l}\text { Kelaya } \\
\text { kan }\end{array}$ \\
\hline 1 & Benteng & 27132 & 200501 & 34 & 26 & Naik 7 kelas & 1 & Layak \\
2 & Benteng & 27200 & 375000 & 34 & 22 & Naik 7 kelas & 5 & Layak \\
3 & Surutanga & 44197 & 500000 & 32 & 21 & Naik 7 kelas & 4 & Layak \\
4 & Salokoe & 13464 & 300000 & 36 & 24 & Naik 7 kelas & 5 & Layak \\
5 & Pontap & 6732 & 500000 & 38 & 21 & Naik 7 kelas & 10 & Layak \\
6 & Pontap & 103000 & 400000 & 29 & 22 & Naik 7 kelas & 0 & Layak \\
7 & Salotellue & 20400 & 500000 & 35 & 21 & Naik 7 kelas & 7 & Layak \\
8 & Salotellue & 26010 & 588235 & 34 & 19 & Naik 7 kelas & 8 & Layak \\
9 & Ponjalae & 12400 & 200000 & 36 & 26 & Naik 7 kelas & 3 & Layak \\
10 & Ponjalae & 3696 & 650000 & 40 & 19 & Naik 7 kelas & 13 & Layak \\
\hline
\end{tabular}

Begitupula dengan kondisi kelas tanah dan nilai tanah di Kecamatan Wara. Terdapat selisih kelas tanah di setiap kelurahan lokasi penelitian di kecamatan Wara Timur (Tabel 2). Temuan di lokasi penelitian menunjukkan nilai tanah berdasarkan harga pasar tergolong tinggi. Nilai tanah tertinggi berada di kelurahan Lagaligo sebesar Rp. 3.000.000. Kelurahan Lagaligo adalah salah satu pusat kota dan bisnis di Kota Palopo. Luas wilayah Kecamatan Wara adalah $1149 \mathrm{Km} 2$ dimana seluruhnya terletak di daerah dataran rendah (BPS, 2019b). Temuan penelitian di Kecamatan Pedurungan Kota Semarang menunjukkan bahwa nilai tanah dari data NJOP (Nilai Jual Objek Pajak) tanah dengan nilai tertinggi sebesar Rp 5.095.000 yang terletak disepanjang Jl. Majapahit di Kelurahan Gemah dengan dominasi penggunaan lahan adalah perdagangan (Amelia et al., 2015). 
Tabel 2 Kondisi tanah dan kelas tanah di Kecamatan Wara

\begin{tabular}{lllllllll}
\hline $\begin{array}{c}\text { Res } \\
\text { pon } \\
\text { den }\end{array}$ & Kelurahan & $\begin{array}{c}\text { Nilai } \\
\text { Tanah } \\
\text { yang } \\
\text { Lalu }\end{array}$ & $\begin{array}{c}\text { Nilai Jual } \\
\text { Tanah } \\
\text { Saat ini } \\
(/ \mathrm{M})\end{array}$ & $\begin{array}{c}\text { Kelas } \\
\text { Berdasa } \\
\text { rkan } \\
\text { NJOP }\end{array}$ & $\begin{array}{c}\text { Kelas } \\
\text { Saat } \\
\text { Ini }\end{array}$ & $\begin{array}{c}\text { Jumlah } \\
\text { Kenaikan } \\
\text { Kelas }\end{array}$ & $\begin{array}{c}\text { Selisih } \\
\text { Kelas }\end{array}$ & Ket \\
\hline 11 & Dangerakko & 108000 & 500000 & 29 & 21 & Naik 7 kelas & 1 & Layak \\
12 & Dangerakko & 31050 & 2500000 & 33 & 4 & Naik 7 kelas & 21 & Layak \\
13 & Laga Ligo & 82800 & 2500000 & 30 & 4 & Naik 7 kelas & 19 & Layak \\
14 & Laga Ligo & 97000 & 3000000 & 29 & 1 & Naik 7 kelas & 21 & Layak \\
15 & Boting & 58100 & 570000 & 31 & 20 & Naik 7 kelas & 4 & Layak \\
16 & Boting & 71010 & 1500000 & 31 & 11 & Naik 7 kelas & 13 & Layak \\
17 & Pajalesang & 11142 & 1000000 & 37 & 15 & Naik 7 kelas & 16 & Layak \\
\hline
\end{tabular}

Sama halnya di kecamatan Wara Utara, terdapat selisih kelas tanah di setiap kelurahan (Tabel 3). Nilai tanah tertinggi berdasarkan harga pasar di Kecamatan Wara Utara berada di Kelurahan Batupasi dan Luminda masing-masing sebesar Rp. 3000.000. Tingginya nilai tanah tersebut karena kedua wilayah tersebut termasuk pusat kota dan bisnis. Namun terdapat kelurahan yang masuk daerah pesisir yaitu Sabbamparu, Salubulo, dan Penggoli.

Tabel 3 Kondisi tanah dan kelas tanah di Kecamatan Wara Utara

\begin{tabular}{lllllllll}
\hline $\begin{array}{c}\text { Res } \\
\text { pon } \\
\text { den }\end{array}$ & Kelurahan & $\begin{array}{c}\text { Nilai } \\
\text { tanah } \\
\text { yang lalu }\end{array}$ & $\begin{array}{c}\text { Nilai } \\
\text { tanah } \\
\text { saat ini } \\
(/ \mathrm{m})\end{array}$ & $\begin{array}{c}\text { Kelas } \\
\text { berdas } \\
\text { arkan } \\
\text { NJOP }\end{array}$ & $\begin{array}{c}\text { Keteran } \\
\text { gan } \\
\text { kelas } \\
\text { saat ini }\end{array}$ & $\begin{array}{c}\text { Jumlah } \\
\text { Kenaikan } \\
\text { Kelas }\end{array}$ & $\begin{array}{c}\text { Selisih } \\
\text { kelas }\end{array}$ & Ket \\
\hline 18 & Batupasi & 29982 & 3000000 & 34 & 1 & Naik 7 kelas & 26 & Layak \\
19 & Penggoli & 42840 & 400000 & 32 & 22 & Naik 7 kelas & 3 & Layak \\
20 & Penggoli & 10200 & 1000000 & 37 & 15 & Naik 7 kelas & 15 & Layak \\
21 & Luminda & 91512 & 1000000 & 29 & 15 & Naik 7 kelas & 7 & Layak \\
22 & Luminda & 16830 & 3000000 & 36 & 1 & Naik 7 kelas & 28 & Layak \\
23 & Pate'ne & 30492 & 2270000 & 34 & 7 & Naik 7 kelas & 20 & Layak \\
24 & Pate'ne & 14570 & 560000 & 36 & 20 & Naik 7 kelas & 9 & Layak \\
25 & Salobulo & 149328 & 2500000 & 12 & 5 & Naik 7 kelas & 0 & Layak \\
& & 0 & & & & & & Naik 7 kelas \\
26 & Sabbamparu & 12512 & 367000 & 36 & 22 & Naik 7 kelas & 16 & Layak \\
27 & Sabbamparu & 8000 & 1000000 & 38 & 15 & & Layak \\
\hline
\end{tabular}


Secara keseluruhan terdapat selisih kelas tanah di setiap kelurahan lokasi penelitian di kecamatan Wara Barat (Tabel 4). Sedangkan nilai tanah berdasarkan harga pasar tertinggi sebesar Rp.466.000 berada di kelurahan To Marundung dan terendah Rp.10.000 berada di Kelurahan Battang yang wilayahnya adalah pegunungan. Umumnya kondisi topografi seluruh kelurahan di kecamatan Wara Barat adalah bukan pesisir, bukan pusat kota dan beberapa wilayahnya adalah pegunungan dan penggunaaan lahan didominasi pertanian dan perkebunan (BPS, 2019a).

Temuan (Santoso, Fitriarestu Galuh, Suprayogi Andri, 2017) menunjukkan bahwa nilai tanah terendah berdasarkan survei transaksi harga tanah sebesar Rp 269. 000 terdapat pada zona 33 terendah terletak di Kelurahan Sidorejo Kidul bagian timur dengan dominasi penggunaan lahan berupa lahan pertanian. Di kecamatan Semarang Selatan terdapat 54 ZNT berdasarkan survei transaksi harga tanah dengan nilai terendah sebesar Rp 1.106.000 per meter pada zona 11 dan nilai tertinggi sebesar Rp 75.564.000 per meter pada zona 48. Nilai terendah terdapat di kelurahan Randusari dengan dominasi penggunaan lahan adalah pemukiman (perkampungan), sedangkan nilai tertinggi terletak di sepanjang Jl. Pandanaran dengan dominasi penggunaan lahan adalah perdagangan (Mayangsari, Fika Meilina, Subiyanto, Sawitri, Suprayogi, 2015).

Tabel 4 Kondisi tanah dan kelas tanah di Kecamatan Wara Barat

\begin{tabular}{llccccccc}
\hline $\begin{array}{l}\text { Res } \\
\text { pon } \\
\text { den }\end{array}$ & Kelurahan & $\begin{array}{c}\text { Nilai } \\
\text { Tanah } \\
\text { Yang } \\
\text { Lalu }\end{array}$ & $\begin{array}{c}\text { Nilai } \\
\text { Tanah } \\
\text { Saat Ini } \\
(\text { M) }\end{array}$ & $\begin{array}{c}\text { Kelas } \\
\text { Berdas } \\
\text { arkan } \\
\text { NJOP }\end{array}$ & $\begin{array}{c}\text { Kelas } \\
\text { Saat } \\
\text { Ini }\end{array}$ & $\begin{array}{c}\text { Jumlah } \\
\text { Kenaikan } \\
\text { Kelas }\end{array}$ & $\begin{array}{c}\text { Selisih } \\
\text { Kelas }\end{array}$ & Ket \\
\hline 28 & Battang & 6412 & 10000 & 38 & 37 & Naik 3 kelas & -2 & Layak \\
29 & Lebang & 5019 & 16556 & 39 & 36 & Naik 3 kelas & 0 & Layak \\
30 & Lebang & 1811 & 32051 & 42 & 33 & Naik 3 kelas & 6 & Layak \\
31 & $\begin{array}{l}\text { Padang } \\
\text { Lambe }\end{array}$ & 7150 & 18750 & 38 & 35 & Naik 3 kelas & 0 & Layak \\
32 & $\begin{array}{l}\text { To } \\
\text { Marundung } \\
33\end{array}$ & 106592 & 466000 & 29 & 21 & Naik 3 kelas & 5 & Layak \\
& $\begin{array}{l}\text { To } \\
\text { Marundung }\end{array}$ & 31230 & 255000 & 34 & 25 & Naik 3 kelas & 6 & Layak \\
\hline
\end{tabular}

Berdasarkan uraian kondisi nilai dan kelas tanah di empat kecamatan (Tabel 1-4), maka ajuan kenaikan NJOP yang dibuat oleh Bapenda Kota Palopo di empat kecamatan tersebut layak untuk dilaksanakan. Terdapat beberapa alasan mengapa perubahan nilai NJOP Kota Palopo mendesak untuk dilakukan meliputi: (1) nilai NJOP tanah per meter jauh lebih rendah dari nilai jual atau pasar saat, (2) nilai NJOP lama tidak digunakan lagi sebagai patokan dalam kegiatan jual beli, (3) kenaikan kelas setiap kelurahan layak jika ditinjau berdasarkan lokasi (jarak dengan fasum, aktivitas ekonomi dll), (4) nilai NJOP lama, tidak ada wilayah di Kota Palopo yang masuk dalam kategori kelas 1 dalam standarisasi kelas nilai tanah, (5) faktanya terdapat daerah misalnya, di Jalan Andi Djemma (depan poros) yang harga jualnya telah mencapai angka Rp 3.000.000 sampai Rp 
3.500.000, (6) fakta lain ditemukan beberapa lokasi di kelurahan yang lokasinya telah berubah menjadi pusat kegiatan ekonomi, jalan poros atau pendidikan sehingga wilayahwilayah tersebut sangat layak untuk dilakukan penyesuaian NJOP dan ZNTnya. Penyesuaian kenaikan NJOP tersebut, diharapkan pendapatan Asli Daerah (PAD) yang bersumber dari pajak bumi dan bangunan sektor perkotaan dapat lebih optimal.

Survei nilai tanah di Kabupaten Sragen menemukan adanya perbedaan nilai tanah pada kawasan wilayah berbeda. Pada kawasan pusat kota kecamatan Gemolong zona nilai tanah tertinggi sebesar Rp. 10.000.000,00 yang terletak di simpul kelas jalan kolektor Sragen-Boyolali dan Solo-Purwodadi yang merupakan kawasan area industri barang dan jasa. Zona nilai tanah terendah sebesar Rp. 200.000,00 terletak pada zona 35 di kelurahan Kragilan dengan penggunaan tanah berupa sawah. Pada kawasan pusat kota kecamatan Sragen zona nilai tanah tertinggi sebesar Rp. 16.500.000,00 yang terletak di jalan arteri Sragen (kawasan area industri barang dan jasa). Sedangkan zona nilai tanah terendah merupakan lahan persawahan sebesar Rp. 590.000,00 yang terletak di kelurahan Nglorog (Yuristasari, Anggraeni Nadia, Subiyanto, Sawitri, Wijaya, 2016).

Faktor aksesibilitas mempengaruhi harga nilai tanah misalnya: variable jarak pasar, rumah sakit, kantor pemerintahan, jarak sekolah dan jarak jalan memiliki korelasi negatif yang berarti adalah semakin jauh jarak bidang tanah terhadap variabel-variabel tersebut maka semakin murah harga tanah tersebut. Sementara varibel lebar jalan memiliki korelasi positif yang berarti semakin lebar jalan yang berada di dekat suatu bidang tanah maka semakin tinggi harga tanah tersebut (Kinasih, Ardianti Putri, Subiyanto, Sawitri, Sudarsono, 2019).

Penelitian ini juga menemukan beberapa kondisi tanah yang telah ditimbun memiliki nilai jual yang jauh lebih tinggi dibandingkan dengan tanah di sekitarnya yang belum ditimbun sehingga mempengaruhi nilai tanah tersebut. Temuan (Hayu, Sisvinta Bodro, Suprayogi Andri, 2014) menunjukkan bahwa keseluruhan kenaikan tanah disebabkan oleh terjadinya pembangunan pusat kegiatan baru seperti: perbelanjaan, pemukiman, perkantoran dan bangunan-bangunan baru seperti pariwisata (hotel, jasa hiburan dan jasa lainnya). Perubahan kenaikan penggunaan lahan terbesar terdapat pada permukiman dan terendah kawasan industri, sedangkan penurunan penggunaan lahan tertinggi terdapat pada sawah dan terendah pada kebun (Putri Hapsari, Dwi Erni, Sudarsono, Bambang, Bashit, 2019). Perubahan lahan dalam rentang waktu tahun 2010 sampai 2013 di kecamatan Tembalang kota Semarang akibat perubahan penggunaan lahan terjadi di 19 titik dengan empat tipe perubahan yaitu tegalan menjadi perumahan, tegalan menjadi tanah kosong, sawah menjadi perumahan, tanah kosong menjadi perumahan (Kusumo, Diba Vara Dimitri Agatha, Kahar, Sutomo, Subiyanto, 2015).

Fakta di lokasi penelitian juga menunjukkan terdapat selisih kelas tanah berdasarkan NJOP dengan kelas tanah tanah saat ini berdasarkan Keputusan Menteri Keuangan No 523/KMK.04/1998 di setiap Kecamatan di Kota Palopo. Selain itu beberapa temuan penelitian dapat dipertimbangkan Bapenda kota Palopo terkait penyesuaian ZNT diantaranya: jual beli tanah di masyarakat kebanyakan berdasarkan kesepakatan harga antara penjual dan pembeli, nilai NJOP tidak dijadikan patokan dalam jual beli tanah dan mayoritas kegiatan jual beli tanah tidak terlapor ke Kelurahan setempat. 


\section{Simpulan dan saran}

Secara umum terdapat selisih kelas tanah setiap kecamatan di lokasi penelitian sehingga pemutakhiran kenaikan kelas tanah yang dilakukan Bapenda layak untuk dilaksanakan. Terdapat perbedaan antara nilai tanah berdasarkan NJOP dengan nilai tanah berdasarkan harga pasar di setiap kecamatan yang berbasis di kelurahan. Nilai tanah berdasarkan harga pasar di semua kelurahan setiap kecamatan tergolong tinggi. Nilai tanah tertinggi sebagian besar berada kecamatan Wara sebagai pusat ibu kota Palopo dengan penggunaan lahan sebagai pusat perdagangan dan jasa. Sedangkan nilai tanah terendah berada di kecamatan Wara Barat (pinggiran kota Palopo) dengan penggunaan lahan mayoritas untuk kegiatan pertanian, perkebunan dan peternakan. Secara Keseluruhan nilai NJOP yang ditetapkan pemerintah kota Palopo melaui Dinas Pendapatan Daerah (Bapenda) layak untuk dilaksanakan. Penelitian merekomendasikan bahwa Nilai NJOP yang baru yang telah ditetapkan Bapenda dapat ditetapkan dan dijadikan patokan baku untuk proses jual beli tanah di kota Palopo dan setiap transaksi tanah agar dilaporkan ke kelurahan untuk dijadikan arsip kelurahan dan ajuan satu data NJOP bagi seluruh stakeholder di Kota Palopo terkait pertanahan.

\section{Ucapan Terima Kasih}

Terima kasih kami sampaikan kepada Pemerintah Kota Palopo melalui Badan Penelitian dan Pengembangan Daerah (Balitbangda) yang telah mendukung penelitian ini khususnya dalam hal pendanaan.

\section{Daftar Rujukan}

Amelia, N., Subiyanto, S., \& Wijaya, A. (2015). Pemetaan Zona Nilai Tanah Untuk Menentukan Nilai Jual Objek Pajak (NJOP) Menggunakan Sistem Informasi Geografis Di Kecamatan Pedurungan, Kota Semarang. Jurnal Geodesi Undip, 4(1), 160-171.

Aprianti, B., Waljiyanto. (2013). Penilaian Ulang Objek Pajak Bumi Dan Bangunan Berbasis Peta Zona Nilai Tanah. In Skripsi.

Bayhaki, Sunaryo, Kurnia, Dedy, Y. (2019). Pembuatan Zona Nilai Tanah Untuk Updating Nilai Jual Objek Pajak Bumi Dan Bangunan Perdesaan Dan Perkotaan (Studi Kasus : Kelurahan Pembataan, Kecamatan Murung Pudak, Kabupaten Tabalong). http://eprints.itn.ac.id/1466/

BPS. (2019a). Kecamatan Wara Barat Dalam Angka.

BPS. (2019b). Kecamatan Wara Dalam Angka. In BPS.

BPS. (2019c). Kecamatan Wara Timur Dalam Angka. In BPS.

Harjanto, B., \& Hidayati, W. (2016). Konsep Dasar Penilaian Properti (2nd ed.). BPFE. https://opac.perpusnas.go.id/DetailOpac.aspx?id=968550

Hayu, Sisvinta, B., Suprayogi, A. (2014). Identifikasi Pengaruh Pola Perubahan Lahan Terhadap Zona Nilai Tanah Di Kecamatan Ungaran Barat Kabupaten Semarang. Jurnal Geodesi Undip, $3(1), 83180$.

Heriyanto, Rifai, A. T. (2016). EPERTORIUM Jurnal Ilmiah Hukum Kenotariatan. Repertorium: Jurnal Ilmiah Hukum Kenotariatan, 5(2). www.notariat.fh.unsri.ac.id

Karakayaci, Z. (2018). Regression Analysis for the Factor Affecting on Farm Land / Urban Land Value in Urban Sprawl Kentsel Saçaklanma Alanlarındaki Arazilerin Değerini Etkileyen Faktörler için Regresyon. Turkish Journal of Agriculture - Food Science and Technology, 6(10), 1357-1361.

Kinasih, Ardianti, P., Subiyanto, Sawitri, Sudarsono, B. (2019). Analisis Faktor Aksesibilitas Terhadap Zona Nilai Tanah Di Kawasan Pusat Kota Untuk Meningkatkan Potensi PAD (Studi Kasus : Kecamatan Kendal, Kabupaten Kendal). 8(1), 150-159.

Kusumo, Diba, V. D. A., Kahar, Sutomo, Subiyanto, S. (2015). Analisis Perubahan Zona Nilai Tanah Akibat Perubahan Penggunaan Lahan Di Kecamatan Tembalang Kota Semarang. I Wayan Eka Swastikayana, P42, 4(1), 42.

Maimanah, Z. A., Ispriyarso, B., Prananingtyas, P. (2019). Pemanfaatan Dokumen Zona Nilai Tanah (Znt) Sebagai Dasar Pemungutan Penerimaan Negara Bukan Pajak. Notarius, 12(1), 
332-344. https://doi.org/10.14710/nts.v12i1.26974

Mayangsari, Fika, M., Subiyanto, Sawitri, Suprayogi, A. (2015). Pemetaan Zona Nilai Tanah Berdasarkan Harga Pasar Untuk Menentukan Nilai Jual Objek Pajak (NJOP) Menggunakan Sistem Informasi Geografis (Studi Kasus : Kecamatan Semarang Selatan, Kota Semarang). 4, 164-173.

Putri, H., Dwi Erni, Sudarsono, Bambang, Bashit, N. (2019). Analisis Pengaruh Perubahan Penggunaan Lahan Akibat Perpindahan Fasilitas Publik Terhadap Zona Nilai Tanah Di Kecamatan Boyolali Kabupaten Boyolali. Jurnal Geodesi Undip, 8(1), 368-377.

Ratna, K., Udiana, W. D. (2016). Kajian Nilai Tanah Berdasarkan Harga Pasar Menggunakan Metode Regresi Linier Berganda (Studi Kasus: Kecamatan Gunung Anyar, Surabaya). Jurnal Teknik ITS, 5(2), 2-5. https://doi.org/10.12962/j23373539.v5i2.17183

Santoso, Fitriarestu, G., Suprayogi Andri, S. B. (2017). Pembuatan Peta Zona Nilai Tanah Untuk Menentukan Nilai Objek Pajak Berdasarkan Harga Pasar Menggunakan Aplikasi SIG (Studi Kasus : Kecamatan Tingkir, Kota Salatiga). Jurnal Geodesi Undip, 6(4), 18-25.

Sutawijaya, A. (2004). Tanah Sebagai Dasar Penilaian Nilai Jual Obyek Pajak (Njop) Pbb Di Kota $\begin{array}{llll}\text { Semarang. Journal } & \text { Ekonomi }\end{array}$ https://journal.uii.ac.id/index.php/JEP/article/viewFile/625/551

Yang, Z., Li, C., Fang, Y. (2020). Driving factors of the industrial land transfer price based on a geographicallyweighted regression model: Evidence from a rural land system reform pilot in China. Land, 9(1). https://doi.org/10.3390/land9010007

Yuristasari, Anggraeni, N., Subiyanto, Sawitri, Wijaya, P. A. (2016). Analisis Faktor Aksesibilitas Terhadap Perbedaan Nilai Tanah Di Kawasan Pusat Kota Kecamatan Gemolong Dan Kecamatan Sragen Kabupaten Sragen. Jurnal Geodesi Undip, 5(1), 316-325. 